\title{
DAMPAK PROGRAM KRPL (KAWASAN RUMAH PANGAN LESTARI) TERHADAP POLA PANGAN HARAPAN (PPH)
}

\author{
Muh. Aniar Hari Swasono ${ }^{1}$ )Nur Cholilah $^{2}$ ) \\ Fakultas Pertanian Universitas Yudharta Pasuruan \\ Email : hariswasono@gmail.com
}

\begin{abstract}
ABSTRAK
Penelitian ini bertujuan untuk menganalisis dampak dari program KRPL terhadap gizi masyarakat melalui analisis Pola Pangan Harapan. Gizi yang tercukupi sesuai anjuran tidak hanya dilihat dari aspek kuantitas tetapi juga perlu dianalisis dari aspek kualitas. Kualitas gizi dapat diketahui dari perhitungan Pola Pangan Harapan (PPH) yang menggunakan skor ideal 100 sesuai anjuran WNPG dan Badan Pangan Nasional. Berdasarkan PPH, variabel yang diteliliti meliputi jenis pangan, partisipasi konsumsi pangan, frekuensi konsumsi, asal pangan dan AKE. Pengumpulan data dilakukan dengan menggunakan data primer dan data sekunder. Analisis data menggunakan dari setiap konsumsi dikonversi dalam Daftar Konsumsi Bahan Makanan (DKBM) nasional. Hasil analisis PPH di KRPL Desa Pucangsari adalah kurang dari skor ideal, yaitu 70,8\% sehingga belum dikatakan ideal. Skor tertinggi dari semua kelompok pangan adalah kelompok sayur dan buah yaitu 109,94 dari skor maksimal 30. Kelompok sayur dan buah mayoritas dari hasil pekarangan secara mandiri. Artinya, program KRPL berdampak dalam penganekaragaman pangan meskipun belum mencapai ideal.
\end{abstract}

Kata Kunci: KRPL, Kelompok Pangan, PPH

\section{PENDAHULUAN}

Faktor utama perwujudan program KRPL adalah bahwa ketahanan pangan nasional dimulai dari bawah, yaitu dimana Rumah Tangga merupakan objek dasar acuan terbentuknya konsep ketahanan pangan. Bila satu rumah tangga dapat mengantisipasi pemenuhan kebutuhan pangan secara mandiri dan dapat mengkonsumsi pangan yang beragam, maka prinsip perubahan pola konsumsi masyarakat Indonesia dapat mengindikasikan terbentuknya ketahanan pangan yang berkembang secara signifikan, mandiri dan dapat mengurangi kuota impor akan beras.

Salah satu fungsi pengembangan ketahanan pangan itu sendiri selain dari segi ekonomi rumah tangga adalah fungsi adanya upaya dalam konteks pemenuhan kebutuhan gizi masyarakat, khususnya kalangan menengah kebawah. Dengan adanya pola konsumsi beragam dan tidak hanya mengutamakan beras sebagai makanan wajib diharapkan gizi masyarakat tetap terpenuhi sesuai anjuran standart gizi yang diberlakukan sehingga sumberdaya manusia terbentuk ideal.

Gizi yang seimbang tidak hanya dilihat dari jumlah atau kuantitas pangan yang dikonsumsi, namun juga perlu dilihat dari segi keragaman pangan yang dikonsumsi. Pangan beragam yang dikonsumsi akan mencerminkan keragaman zat gizi yang terpenuhi. Pola konsumsi pangan yang memenuhi gizi ideal dapat dianalisis dari Pola Pangan Harapan yang menjadi acuan 
untuk menilai tingkat keragaman konsumsi pangan dengan skor 100 sebagai pola yang ideal. PPH merupakan suatu metode kinerja keragaman konsumsi pangan pada suatu waktu untuk komunitas tertentu (Pranoto, 2008).

KRPL percontohan di Pasuruan dilaksankan di Desa Pucangsari Kecamatan Purwodadi, dengan di organisir oleh Kelompok Wanita Tani Mayangsari dan dibantu perangkat pemerintah setempat. KRPL sudah berjalan 1 tahun 3 bulan tersebut telah memiliki anggota sebanyak \pm 180 RT, kolam ikan lele yang bertambah hingga $\pm 20 \mathrm{kolam} / \mathrm{kk}$ dan ternak ayam sudah dimiliki \pm 20 RT. KRPL Desa Pucangsari lebih didominasi tanaman hortikultura, seperti cabe, tomat, terong, mentimun dan sayuran yang mudah ditanam.

KRPL Desa Pucangsari diharapkan dapat terwujud nyata dalam membantu pemenuhan gizi rumah tangga dengan mengonsumsi pangan lokal dari pekarangan sendiri, sehingga menurunkan angka ketergantungan akan beras dan meningkatkan partisipasi pangan untuk komoditas nonberas lainnya yang didapat secara mandiri melalui program KRPL tersebut. Oleh karena itu, peneliti melakukan observasi dari aspek pola konsumsi dan gizi di salah satu KRPL Desa Pucangsari yaitu di Dusun Sudimoro.

Permasalahannya, Bagaimanakah dampak program Kawasan Rumah Pangan Lestari di Desa Pucangsari Kecamatan
Purwodadi Kabupaten Pasuruan terhadap Pola Pangan Harapan.

\section{METODE PENELITIAN}

\section{Prosedur Penelitian}

Prosedur penelitian dalam pengambilan data konsumsi pangan menggunakan metode food record (pencatatan) yang berupa tabel kuisioner dan diiisi oleh masing-masing responden dalam rumah tangga di kawasan RPL. Pencatatan porsi konsumsi dilakukan selama 5 (lima) hari secara berurutan dan mengelompokkan (clustering) data berdasarkan karakteristik masing-masing. Secara prinsip terdapat tiga tahapan yang perlu dilakukan dalam pengolahan data pemantauan konsumsi pangan, yaitu pengkodean (coding), pemasukan (entry).

\section{Analisis Data}

Dengan pendekatan PPH ini mutu konsumsi pangan penduduk dapat dilihat dari skor pangan (dietary score) dan dikenal sebagai skor PPH. Semakin tinggi skor PPH, konsumsi pangan semakin beragam dan seimbang (AnonimusG, 2013). Dalam menghitung skor dan komposisi PPH aktual (susunan PPH) dilakukan dengan mengikuti 7 langkah meliputi:

1) Konversi bentuk, jenis, dan satuan.

2) Pengelompokan pangan menjadi 9 kelompok.

3) Menghitung konsumsi energi menurut kelompok pangan. 
4) Menghitung total konsumsi energi dengan cara menjumlahkannya dari kelompok pangan 1 sampai dengan 9

5) Menghitung kontribusi energi menurut AKG (AKE konsumsi untuk rata-rata nasional tahun 2004 adalah 2000 kkal/kap/hari) dari setiap kelompok pangan. dalam bentuk persen (\%).

6) Menghitung skor PPH
7) Menghitung total skor mutu konsumsi pangan.

\section{HASIL DAN PEMBAHASAN}

Hasil analisis keragaman pangan di lokasi KRPL Mayangsari dengan mengacu proporsi ideal PPH nasional disajikan pada tabel berikut :

Tabel 1. Hasil Skor PPH Program KRPL Desa Pucangsari

\begin{tabular}{|c|l|c|c|c|c|c|c|c|c|}
\hline No & \multicolumn{1}{|c|}{$\begin{array}{c}\text { Kelompok } \\
\text { Pangan }\end{array}$} & $\begin{array}{c}\text { Energi } \\
\text { Aktual }\end{array}$ & $\%$ Aktual & \% AKE*) & Bobot & $\begin{array}{c}\text { Skor } \\
\text { Aktual }\end{array}$ & $\begin{array}{c}\text { Skor } \\
\text { AKE }\end{array}$ & $\begin{array}{c}\text { Skor } \\
\text { Maks }\end{array}$ & $\begin{array}{c}\text { Skor } \\
\text { PPH }\end{array}$ \\
\hline 1. & Padi-padian & 799,7 & 44,5 & 39,985 & 0.5 & 22,25 & 19,99 & 25.0 & 20 \\
\hline 2. & Umbi-umbian & 7,1 & 0,39 & 0,335 & 0.5 & 0,195 & 0,177 & 2.5 & 0,18 \\
\hline 3. & Pangan Hewani & 101,13 & 5,63 & 5,056 & 2.0 & 11,26 & 10,1 & 24.0 & 10 \\
\hline 4. & Minyak dan Lemak & 2,2 & 0,12 & 0,11 & 0.5 & 0,06 & 0,055 & 5.0 & 0,06 \\
\hline 5. & $\begin{array}{l}\text { Buah/Biji } \\
\text { Berminyak }\end{array}$ & 15,2 & 0,85 & 0,76 & 0.5 & 0,425 & 0,38 & 1.0 & 0,4 \\
\hline 6. & Kacang-kacangan & 308,04 & 17,1 & 15,402 & 2.0 & 34,2 & 30,8 & 10.0 & 10 \\
\hline 7. & Gula & 6,4 & 0,36 & 0,32 & 0.5 & 0,18 & 0,16 & 2.5 & 0,16 \\
\hline 8. & Sayur dan Buah & 439,77 & 24,5 & 21,98 & 5.0 & 122,5 & 109,94 & 30.0 & 30 \\
\hline 9. & Lain-lain & 117,12 & 6,52 & 5,856 & 0.0 & 0 & 0 & 0.0 & 0 \\
\hline & & 1796,6 & 99,97 & 89,833 & 11.5 & 191,07 & 171,62 & 100.0 & 70,8 \\
\hline
\end{tabular}

Sumber : Data Primer Diolah

Keterangan : *) AKE $=2000 \mathrm{kal} / \mathrm{kap} / \mathrm{hari}$

Sudimoro sebesar 70,8 belum bisa dikatakan ideal karena kurang dari skor maksimal, yaitu 100. Kelompok pangan yang melebihi kapasitas ideal PPH adalah dari komoditas sayur dan buah dan kelompok pangan yang memiliki nilai terendah dari skor ideal adalah kelompok minyak dan lemak.

Kuantitas Energi yang dianjurkan adalah $2.000 \mathrm{kkal}$, namun dalam program KRPL tersebut diatas hanya berjumlah 1.796,66 kkal yang berarti asupan kalori masih belum bisa dikatakan tercukupi tetapi masih dalam kapasitas yang bukan berarti deficiency.

\section{Konsumsi Kelompok Padi-Padian}

Secara umum tingkat kualitas konsumsi kelompok padi-padian masih belum bisa dikatakan ideal berdasarkan skor PPH yaitu sebesar 20 dari skor ideal 25. Kelompok padi-padian yang dikonsumsi oleh anggota KRPL Desa Pucangsari terdiri dari beras dan jagung yang mayoritas diproduksi dari lahan sendiri. 
Kecenderungan konsumsi kelompok padipadian yang didominasi beras masih dalam nilai 799,7 kkal sedangkan maksimal energi aktual adalah 1000 kkal dan berarti mempunyai gap sebesar 200,3 kkal/kap/hari. Sehingga disimpulkan dari 25 responden KRPL dapat membantu menekan pangsa konsumsi beras, namun juga perlu meningkatkan pangsa konsumsi jagung dan jenis padi-padian lain sehingga dapat mengkonsumsi ragam pangan dari kelompok padi-padian.

\section{Konsumsi Kelompok Umbi-Umbian}

Sedangkan dari kelompok pangan umbi-umbian memiliki skor sangat jauh dibawah skor PPH yaitu 0,18 dari skor ideal 2,5. Kelompok umbi-umbian yang ditanam di KRPL terdiri dari talas dan singkong, akan tetapi partisipasi konsumsi untuk komoditas umbi hanya di konsumsi sekali dalam masa panen dan sisanya dijual. Untuk kontribusi energi diketahui bahwa nilai energi kelompok umbi-umbian dalam tabel 2 maksimal 120 kkal, sedangkan dalam fakta di KRPL hanya senilai 7,1 kkal sehingga gap yang terjadi adalah (-)112,9 kkal/kap/ha.

\section{Konsumsi Kelompok Pangan Hewani}

Dalam kelompok pangan hewani memiliki skor yang rendah dari skor ideal, yaitu sebesar 10 dari skor ideal PPH 24. Komoditas yang termasuk dalam kelompok pangan hewani KRPL ini antara lain ikan dan telur, hal tersebut dikarenakan program
KRPL memanfaatkan produksi ikan dan telur, ikan dalam KRPL didominasi ikan lele yang mudah untuk dikembangbiakkan.

Untuk kontribusi energi pangan hewani, terjadi selisih sebesar (-)130 kkal/kap/hari. Artinya, kecenderungan untuk mengkonsumsi kelompok pangan hewani masih kurang meskipun beragam jenis ikan yang dikonsumsi, namun kebanyakan memilih kecukupan konsumsi dari produk tahu dan tempe dalam kelompok kacangkacangan.

\section{Konsumsi Kelompok Minyak dan Lemak}

Kelompok pangan minyak dan lemak memiliki nilai paling rendah dari seluruh kelompok pangan yang ada, yaitu sebesar 0,06 dari skor ideal 5. Komoditas yang termasuk dalam kelompok minyak dan lemak adalah minyak goreng yang terserap dalam proses penggorengan, sehingga disimpulkan bahwa anggota KRPL lebih menyukai makanan yang digoreng dari pada makanan non-minyak. Akan tetapi tetap harus ditingkatkan hingga dapat mencapai keseimbangan gizi, karena kontribusi energi ideal untuk minyak dan lemak adalah 200 kkal sedangkan konsumsi KRPL hanya 2,2 kkal/kap/hari.

\section{Konsumsi Kelompok Buah/Biji Berminyak \\ Dalam kelompok buah/biji berminyak memiliki skor 0,4 dibawah skor ideal 1. Komoditas yang menyumbang dalam}


partisipasi kelompok buah/biji berminyak adalah kelapa yang digunakan dalam bentuk santan, namun kebanyakan dari para responden menggunakan santan instan yang dijual. Energi yang terdifersivikasi kurang dari ideal, yaitu sebesar 15,2 dari 60 kkal/kap/hari sehingga dapat disimpulkan bahwa perlu adanya peningkatan partisipasi pangan dalam kelompok biji/buah berminyak.

\section{Konsumsi Kelompok Kacang-Kacangan}

Kelompok

kacang-kacangan memiliki skor yang melebihi kapasitas ideal PPH, yaitu sebanyak 30,8 dari skor ideal 10 sehingga menggunakan skor PPH dalam kecukupan kualitas gizi. Hal tersebut diindikasikan bahwa kelompok pangan dari komoditas kacang-kacangan dikonsumsi lebih banyak oleh para responden yaitu antara lain dalam bentuk tahu dan tempe.
Diversifikasi energi aktual kelompok kacangkacangan sebesar 308,04 kkal/kap/hari melebihi kapasitas energi untuk kacangkacangan hanya $100 \mathrm{kkal} / \mathrm{kap} / \mathrm{hari}$. Faktor yang mempengaruhi adalah karena produk tahu dan tempe merupakan makanan telah terkonsumsi sejak lama, selain harganya murah juga praktis dan enak untuk dikonsumsi.

\section{Konsumsi Kelompok Sayur dan Buah}

Kelompok sayur dan buah adalah kelompok yang memiliki nilai tertinggi dan melebihi skor ideal, yaitu sebesar 109,9 dari skor ideal 30. Komoditas yang termasuk dalam kelompok ini sangat beragam dan tidak hanya didominasi oleh produk pekarangan namun juga dari non-pekarangan, seperti yang dijelaskan dalam gambar berikut.

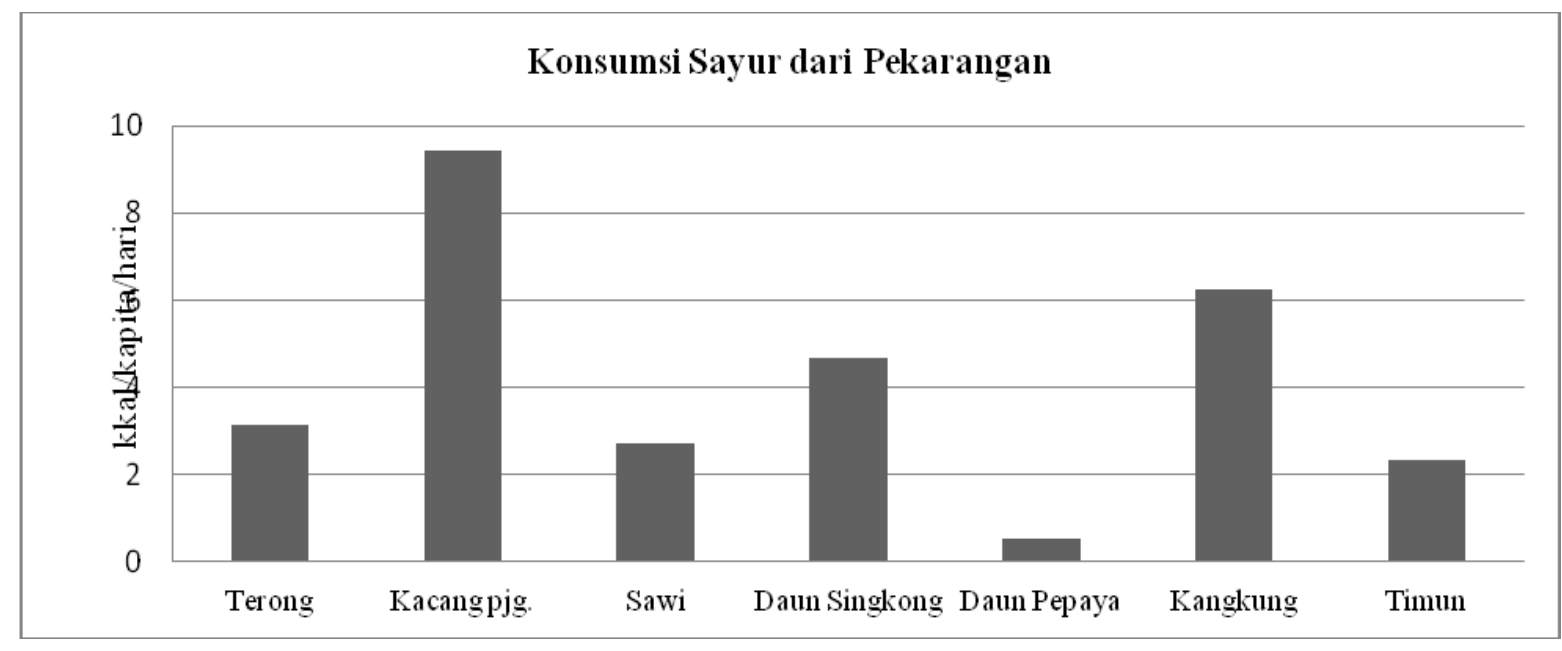

Gambar 1. Rata-Rata Konsumsi Sayur dari Pekarangan 
Komoditas sayur yang memberi jumlah kecil terpenuhi dari komoditas cabe kontribusi energi terbanyak adalah dari dan tomat yang didapat dari pekarangan. komoditas sayur nangka dan kacang Untuk komoditas buah seperti yang panjang, sedangkan untuk komoditas dalam dijelaskan dalam gambar berikut.

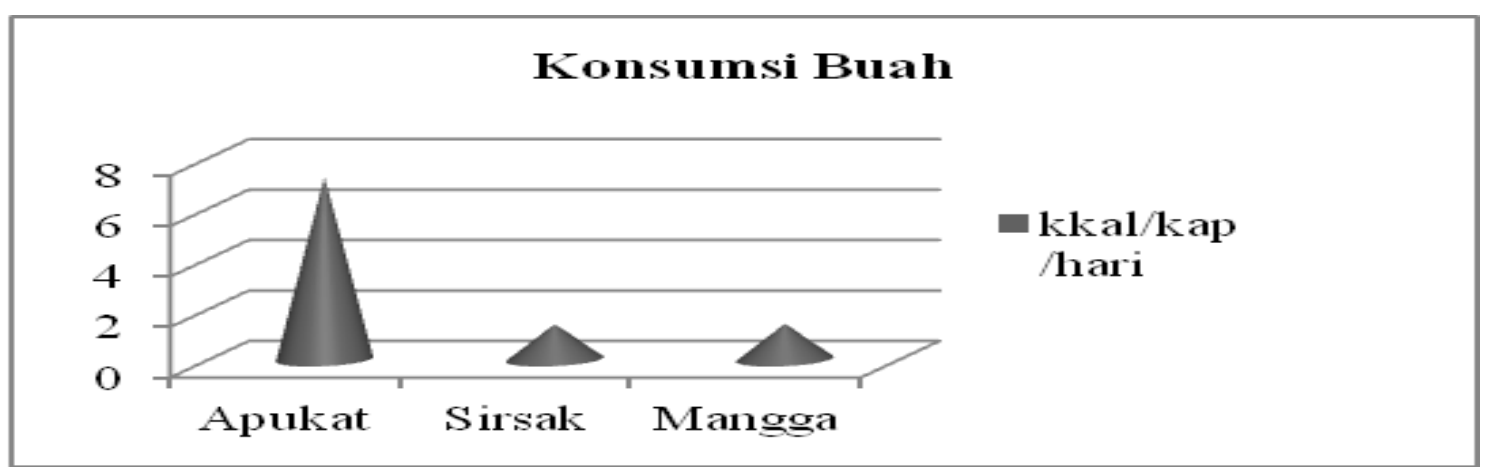

Gambar 7. Rata-Rata Konsumsi Buah

Disimpulkan bahwa program KRPL yang mayoritas anggotanya memproduksi komoditas sayur dan buah sudah mampu memenuhi skor PPH dari kelompok tersebut

\section{Konsumsi Kelompok Gula dan Lain-Lain}

Kelompok pangan gula memiliki skor 0,16 yang jauh dibawah skor ideal 2,5 dan didominasi oleh komoditas gula pasir dengan kontribusi energi sebesar 6,4 kkal, sedangkan ideal energi terdiversifikasi adalah $100 \mathrm{kkal} / \mathrm{kap} / \mathrm{hari}$ Komoditas gula dikonsumsi responden KRPL dalam bentuk campuran dengan menu lain seperti dikonsumsi melalui minuman kopi dan teh, maupun tercampur dalam masakan lain dalam jumlah yang minim.

Dalam KRPL Pucangsari, yang masuk dalam kelompok lain-lain adalah bawang, rempah-rempah, kecap, saos, garam, secara kuantitas dan kualitas partisipasi pangan. Dengan total energi terdiversifikasi sebesar 439,77 kkal/kap/hari melebihi energi ideal $120 \mathrm{kkal} / \mathrm{kap} / \mathrm{hari}$.

mie dan bakso. Kelompok tersebutmerupakan komoditas yang tidak dipenuhi dari program KRPL. Diasumsikan bahwa jenis pangan bawang, rempah-rempah, saos dan kecap termasuk bahan masakan yang harus ada untuk setiap menu masakan, dilihat dari nilai kontribusi yang melebihi maksimal yaitu 117,12 kkal dari nilai maksimal 60 kkal.

\section{KESIMPULAN}

Dari hasil penelitian didapat bahwa jenis pangan bawang, rempah-rempah, saos dan kecap termasuk bahan masakan yang harus ada untuk setiap menu masakan, dilihat dari nilai kontribusi yang melebihi maksimal yaitu 117,12 kkal dari nilai maksimal 60 kkal. 


\section{DAFTAR PUSTAKA}

Anonimus a. 2012. Ketahanan Pangan dan

Pertanian. (http://bkp.jatimprov.go.id/)

Diakses pada : 20 Juni 2013

Anonimus, b. 2012. Serba Serbi Kawasan

Rumah Pangan Lestari Jawa Timur. (http://www.litbang.deptan.go.id/KRPL/ MKRPL-BPTP-Jatim.pdf.) Diakses pada

20 Juni 2013

Anonimus, c. 2012. Panduan KRPL.

(http://www.litbang.deptan.go.id/krpl Ipanduan) Diakses pada : 20 Juni 2013

Anonimus d. 2013. Pusat Penganekaragaman

Konsumsi dan Keamanan Pangan

Pedoman

Analisis

Pangan.

(http://www.promedia/co.

id/p2kp/PedomanAnalisisPangan.pdf)

Diakses: 20 Juni 2013

Anonimus, h. 2012. Pengertian Pola Pangan

Harapan.(http://semutuyet.blogspot.com/ 2012/05/pengertian-pola-pangan harapan.html) Diakses : 10 Juli 2013.

Arikunto, Suharsimi. 2006. Prosedur

Penelitian.

Rineka Cipta, Jakarta.

Djaeni, Achmad. 1985. Ilmu Gizi untuk

Mahasiswa dan Profesi. Dian Rakyat, Jakarta

Firdaus, Azis. 2012. Metode Penelitian.

Jelajah

Nusa, Tangerang

Pranoto, Endro. 2008. Potensi Wilayah

Komoditas Pertanian dalam Mendukung

Ketahanan Pangan Berbasis Agribisnis

Kabupaten Banyumas. Program Pasca

Sarjana, Universitas Diponegoro.

(http://eprints.undip.ac.id/17408/1/Endro_ Pranoto.pdf) Diakses : 20 Juni 2013

Karina Dwi Handini, 2006. Analisis dan

Perencanaan Ketersediaan Pangan

Berdasarkan Pola Pangan Harapan (PPH)

di

Provinsi Kepulauan Bangka Belitung.

Skripsi. Fakultas Pertanian, IPB.

Bandung.

(repository.ipb.ac.id/bitstream/handle/

\section{9/50685/A06kdh.pdf)}

Diakses

pada tanggal 15 Juli 2013)

Purwantini, Tri Bastuti. 2012. Program

KRPL dan

Kabupaten Pacitan : Analisis Dampak

Antisipas ke Depan. Pusat Sosial

Ekonomi

dan Kebijakan Pertanian, Bogor.

(http://pse.litbang.deptan.go.id) Diakses :

20

Juni 2013

Sufa, Ira Guslina. 2013. Permasalahan Gizi

Indonesia

(http://www.tempo.co/read/news/ 2013/07/17/173497219) Diakses : 10

Agustus 2013

Wafa, Indra. 2013. Gambaran Umum Pangan

Dunia. (http://www.paskompas.com)

Diakses pada tanggal 10 Agustus 2013 